\title{
Risk factors associated with postoperative pain and discomfort in oculoplastic surgery with general anesthesia: a prospective study
}

This article was published in the following Dove Press journal: Journal of Pain Research

\author{
Huijing Ye ${ }^{* *}$ \\ Rongxin Chen ${ }^{*}$ \\ Xiufen Lian'* \\ Jingxia Huang ${ }^{2}$ \\ Yuxiang Mao' \\ Rong Lu' \\ Siming $\mathrm{Ai}^{\mathrm{l}}$ \\ Wenfang $\mathrm{Ma}^{\prime}$ \\ Jingyi Lin ${ }^{2}$ \\ Huasheng Yang' \\ Wenjun Guo ${ }^{2}$ \\ 'Department of Orbital Diseases \\ and Ocular Oncology, State Key \\ Laboratory of Ophthalmology, \\ Zhongshan Ophthalmic Center, \\ Sun Yat-sen University, Guangzhou \\ 510060, China; ${ }^{2}$ Department of \\ Anesthesia, State Key Laboratory \\ of Ophthalmology, Zhongshan \\ Ophthalmic Center, Sun Yat-sen \\ University, Guangzhou 510060, China \\ *These authors contributed equally \\ to this work
}

Correspondence: Huasheng Yang Department of Orbital Diseases and Ocular Oncology, State Key Laboratory of Ophthalmology, Zhongshan

Ophthalmic Center, Sun Yat-sen University, Guangzhou 510060, China

Tel +86 $208733 \quad$ I539

Fax +86 2087334825

Email yanghs64@I26.com

Wenjun Guo

Department of Anesthesia, State Key Laboratory of Ophthalmology, Zhongshan Ophthalmic Center, Sun Yatsen University, Guangzhou 510060, China Tel +86 $208733 \quad 1548$

Fax +862087334825

Email wenjun-guo@qq.com
Purpose: To evaluate patient pain and discomfort following oculoplastic surgery performed under general anesthesia and to assess key factors associated with postoperative pain and discomfort.

Methods: A prospective observational cohort study was conducted among 212 consecutive patients who underwent oculoplastic surgery performed under general anesthesia. The patients were assessed according to quantified levels of pain and discomfort postoperatively. Analgesic requests were recorded, and responses were statistically analyzed.

Results: Pain and discomfort after oculoplastic surgery under general anesthesia were reported by $32.1 \%$ and $28.3 \%$ of the patients, respectively; $2.8 \%$ of the patients requested analgesic medication within 18 hours after surgery. The patients who underwent orbital decompression, secondary orbital implantation, and orbital fracture repair were more likely to develop significant postoperative pain and discomfort $(P<0.001)$, and the patients who underwent enucleation/ evisceration during orbital implantation were more likely to develop postoperative discomfort $(P<0.001)$. The predictors of pain were smoking history, prior surgery on the operative eye, and anxiety $(P<0.05)$, and the predictor of discomfort was anxiety $(P<0.05)$.

Conclusion: Patients undergoing oculoplastic surgery tend to experience postoperative pain and discomfort. Anxiety is a risk factor for both postoperative pain and discomfort, while smoking history and prior surgery on the operative eye may be associated with postoperative pain.

Keywords: pain level, discomfort level, ophthalmic surgery, related factors, prevalence, Chinese

\section{Introduction}

Postoperative pain may result in patient discomfort and may decrease patient satisfaction. ${ }^{1}$ Postoperative pain is unacceptable, and increasing efforts have been directed toward pain awareness and pain management. ${ }^{2}$ Therefore, pain management is an important part of patient care after surgery. Ophthalmic surgery is widely believed to cause little or no postoperative pain because it involves less extensive trauma compared with other types of surgery. ${ }^{3}$ Therefore, pain after ophthalmic surgery has been neglected. ${ }^{4}$ However, Lesin et $\mathrm{al}^{5}$ retrospectively analyzed 447 patients and found that complex ophthalmic surgery, such as enucleation, evisceration, and extensive reconstructions, can lead to severe pain after the operation. Henzler et al, ${ }^{3}$ who observed 500 ophthalmic surgery patients, found that patients who had surgery under general anesthesia experienced serious postoperative pain. Furthermore, with the major shift from traditional postoperative hospitalization towards ambulatory surgery on an outpatient basis, patient safety and comfort in the postoperative period are of the utmost importance when evaluating outpatient procedures. ${ }^{6}$ 
However, little attention has been focused on the factors related to postoperative pain and discomfort in oculoplastic surgery under general anesthesia. These factors are important for outcome analysis as we seek to improve not only anatomical results but also the subjective patient experience. ${ }^{7}$ Furthermore, understanding the factors influencing postoperative pain and discomfort may lead to modifications that improve health care delivery. ${ }^{?}$

To learn more about the risk factors of postoperative pain and discomfort after oculoplastic surgery under general anesthesia, we prospectively evaluated the subjective levels of eye pain and discomfort in 212 consecutive patients during the first 24 hours after ophthalmic surgery performed under general anesthesia.

\section{Methods}

\section{Patients}

Consecutive patients who underwent elective ophthalmic surgery and were assessed for pain and discomfort after surgery between March and December 2016 were included. Approval was obtained in accordance with the Declaration of Helsinki and the Ethics Committee of Zhongshan Ophthalmic Center, Sun Yat-sen University. Written informed consent was obtained from each patient.

\section{Inclusion and exclusion criteria}

Patients were screened before surgery. The inclusion criteria for patient recruitment were as follows: (1) oculoplastic surgical procedures, including orbital decompression, orbital tumor extirpation, enucleation or evisceration with orbital implantation, extensive excision of eyelid/conjunctiva/sclera/choroid tumor, secondary orbital implantation, orbital fracture repair, and strabismus surgery; (2) age $\geq 16$ years; and (3) the use of general anesthesia for ophthalmic surgery.

The exclusion criteria were an inability to communicate (including impairment of sensorium), an inability to provide informed consent, and mental illness.

\section{Surgical classification and anesthetic procedures}

Considering the comparable surgical anatomical sites and trauma, operations were divided into seven groups: orbital decompression, orbital tumor extirpation, enucleation or evisceration with orbital implantation, extensive excision of eyelid/conjunctiva/sclera/choroid tumor, secondary orbital implantation, orbital fracture repair, and strabismus surgery. General anesthesia with induction via propofol $(2 \mathrm{mg} / \mathrm{kg})$ and fentanyl $(2 \mu \mathrm{g} / \mathrm{kg})$ was performed in all patients. Anesthesia was maintained with propofol $(6 \mathrm{mg} / \mathrm{kg} / \mathrm{h})$ and remifentanil $(0.15 \mu \mathrm{g} / \mathrm{kg} / \mathrm{min})$. Flurbiprofen axetil was used 20 minutes before the operation for analgesia. Regional anesthesia (retrobulbar block or topical anesthesia) was performed on a few patients based on the clinical condition using an equivalent amount of $0.5 \%$ bupivacaine and $2 \%$ lidocaine.

\section{Study protocol}

One day before surgery, the patients filled out the Self-rating Anxiety Scale (SAS). The patients did not receive any sedative therapy before surgery. Pain scores, discomfort scores, and analgesic medication were recorded after surgery. Pain and discomfort levels were measured using numerical rating scale (NRS) ranging from 0 to 10 , where 0 represents no pain (or discomfort) and 10 represents the worst pain imaginable (or discomfort); this scale has been confirmed to be sensitive and reliable. ${ }^{8-11}$ Discomfort was defined as "sensation other than pain" and included nausea, vomiting, headache, and dizziness. Clinically significant postoperative pain was considered serious pain (NRS score $\geq 5$ ), and clinically significant postoperative discomfort was considered serious discomfort (NRS score $\geq 5$ ) at any time postoperatively. ${ }^{3}$ Postoperative pain and discomfort intensity levels were measured $0,2,6$, 10 , and 24 hours after recovery from general anesthesia. The patients were unrestricted with respect to the receipt of any analgesic medication required. The usual medication was $0.5 \mathrm{~g}$ of paracetamol orally.

\section{Statistical analysis}

To examine the correlation between NRS score and SAS score, and the relationship between pain and discomfort, we calculated Pearson $r$ coefficient. The independent $t$-test, was used for the relative risk ratios (RRs) and 95\% confidence intervals (95\% CIs), which were calculated for the suspected key factors for the risk of having a NRS score $\geq 5$ at any time postoperatively. The differences between pain scores, discomfort scores, and SAS scores with respect to postoperative analgesic requirements were compared using the independent $t$-test and the chi-square test. The level of significance was set at $P<0.05$. SPSS 13.0 (SPSS Inc., Chicago, IL, USA) was used for the statistical analyses.

\section{Results}

A total of 212 consecutive patients who agreed to participate in the study were enrolled. The median age was 46.0 (range, 16.0-80.0) years. There were 132 male and 80 female patients. 


\section{Postoperative pain and discomfort scores}

Postoperatively, 68 patients $(32.1 \%)$ reported significant eye pain, and 60 patients $(28.3 \%)$ reported significant discomfort. The mean levels of pain and discomfort in the first 24 hours after surgery were 2.9 and 2.4, respectively. Groups 1, 5, and 6 (orbital decompression, secondary orbital implantation, and orbital fracture repair) had significantly higher postoperative pain scores than Groups 2, 3, 4, and 7 (Figure 1), with $51.9 \%$ compared with $26.0 \%$ of patients reporting significant pain (RR 3.06, CI 1.60-5.89, $P<0.001$ ). On the other hand, Groups 1, 3, 5, and 6 (orbital decompression, enucleation/evisceration with orbital implantation, secondary orbital implantation, and orbital fracture repair) had significantly higher discomfort scores than Groups 2, 4, and 7 (Figure 2); $41.4 \%$ of the patients in Groups 1, 3, 5, and 6 had significant discomfort, compared with only $19.2 \%$ of the patients in Groups 2, 4, and 7 (RR 2.97, CI 1.60-5.50, $P<0.001)$. The individual risks of developing serious pain and discomfort relative to the remainder of the patient cohort are presented in Table 1 .

\section{Key factors for pain and discomfort development}

Only operations that resulted in significant postoperative pain or discomfort were used for the key factors analysis. Smoking history was shown to be independently associated with an increased likelihood of experiencing postoperative pain at 0 , 2,10 , and 24 hours $(P<0.05)$. Prior surgery on the operative eye was also shown to be associated with an increased likelihood of postoperative pain at 2, 6, 10, and 24 hours $(P<0.05)$, but not at 0 hours. Meanwhile, SAS score was shown to be associated with an increased likelihood of postoperative pain at 6 and 24 hours $(P<0.05)$. Local anesthesia administration was shown to be associated with an increased likelihood of postoperative pain only at 6 hours $(P<0.05)$. However, the other factors showed no statistically significant impact on pain development, as demonstrated by NRS score $\geq 5$ at any time postoperatively (Table 2 ).

SAS score was shown to be associated with an increased likelihood of postoperative discomfort at 2,10 , and 24 hours $(P<0.05)$. However, as shown in Table 3, the other factors

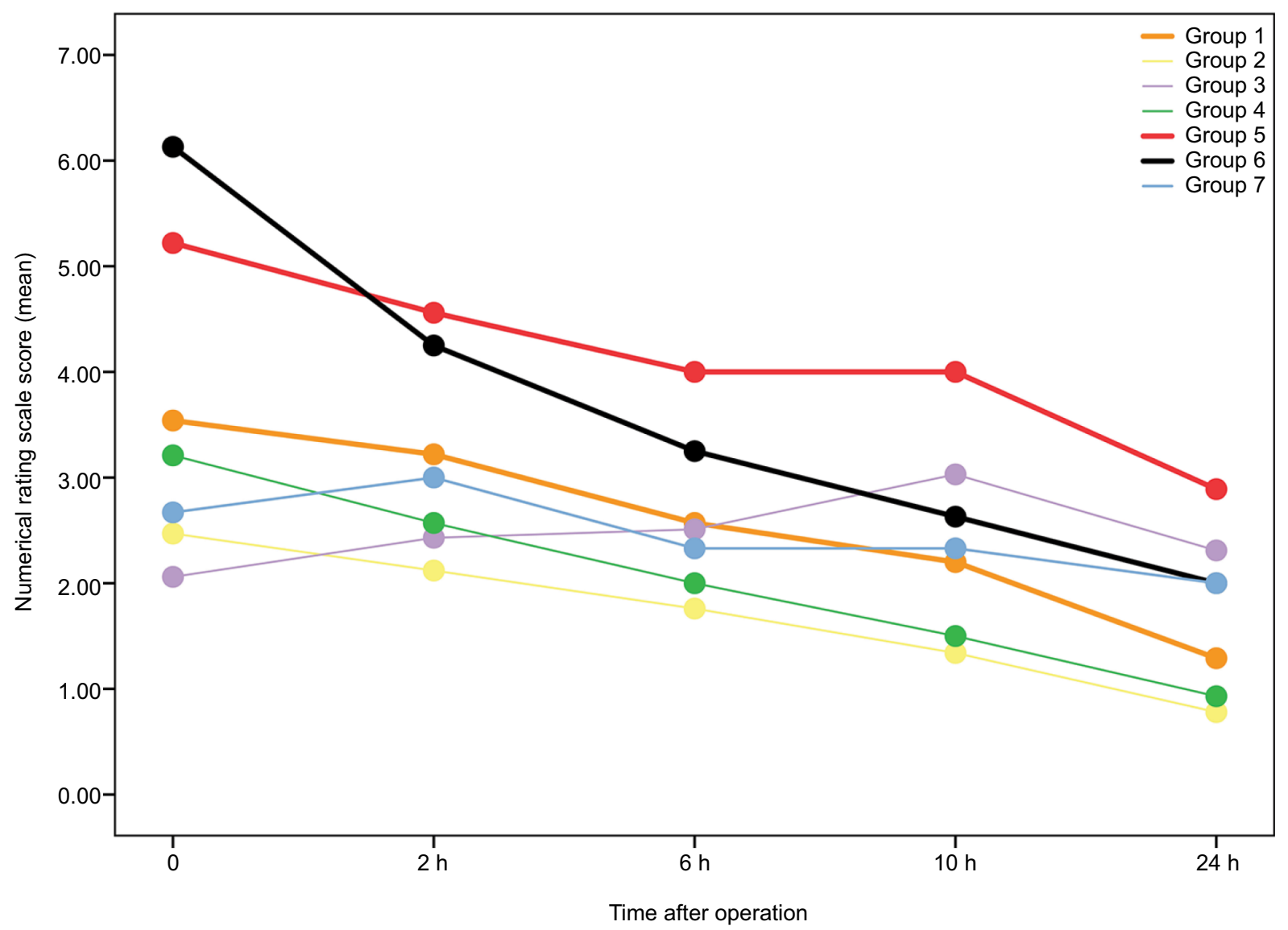

Figure I The mean numerical rating scale (NRS) scores for pain 0 to 24 hours after recovery from general anesthesia.

Note: Groups 1, 5, and 6 had significantly higher postoperative pain scores than Groups 2, 3, 4, and 7. Group I, orbital decompression; Group 2, orbital tumour extirpation; Group 3, enucleation or evisceration with orbital implantation; Group 4, extensive excision of eyelid/conjunctiva/sclera/choroid tumour; Group 5, secondary orbital implantation; Group 6, orbital fracture repair; Group 7, strabismus surgery. 


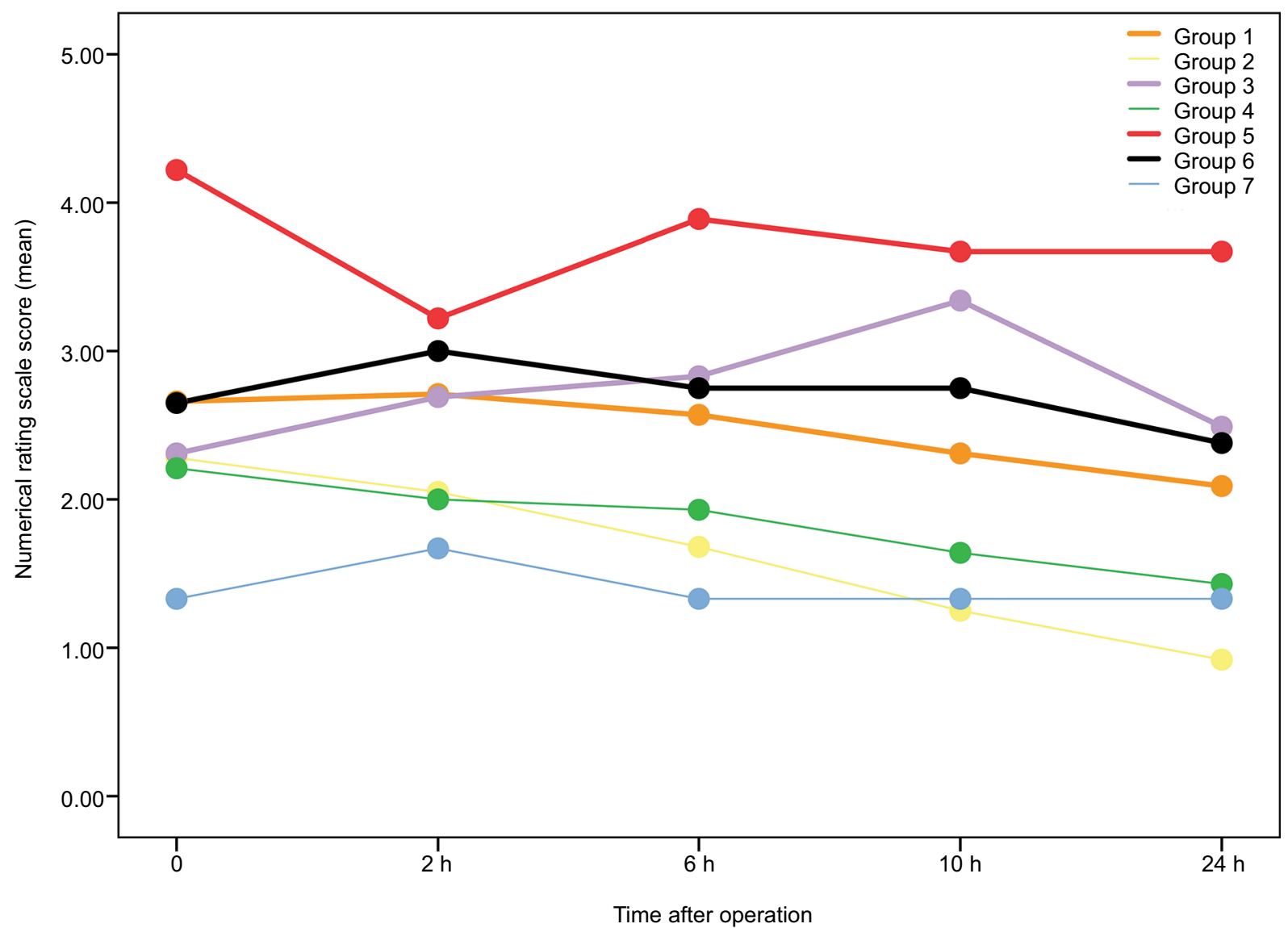

Figure 2 The mean numerical rating scale (NRS) scores for discomfort 0 to 24 hours after recovery from general anesthesia.

Note: Groups I, 3, 5, and 6 had significantly higher postoperative discomfort scores than Groups 2, 4, and 7. Group I, orbital decompression; Group 2, orbital tumour extirpation; Group 3, enucleation or evisceration with orbital implantation; Group 4, extensive excision of eyelid/conjunctiva/sclera/choroid tumour; Group 5, secondary orbital implantation; Group 6, orbital fracture repair; Group 7, strabismus surgery.

Table I Classification of the operations and the relative risks of pain and discomfort

\begin{tabular}{|c|c|c|c|c|c|c|}
\hline Group & Operation & $\mathbf{N}$ & $\begin{array}{l}\text { Significant } \\
\text { pain (\%) }\end{array}$ & $\mathbf{R R}(\mathbf{C l})$ & $\begin{array}{l}\text { Significant } \\
\text { discomfort (\%) }\end{array}$ & $\mathbf{R R}(\mathbf{C l})$ \\
\hline 1 & Orbital decompression & 35 & 45.7 & $2.03(0.97-4.24)$ & 40.0 & $1.90(0.89-4.04)$ \\
\hline 2 & Orbital tumor extirpation & 108 & 23.1 & $0.43(0.24-0.77)$ & 17.6 & $0.33(0.17-0.62)$ \\
\hline 3 & Enucleation/evisceration with orbital implantation & 35 & 31.4 & $0.97(0.44-2.11)$ & 40.0 & $1.90(0.89-4.04)$ \\
\hline 4 & Extensive excision of eyelid/conjunctiva/sclera/choroid tumor & 14 & 35.7 & $1.19(0.38-3.70)$ & 35.7 & $\mathrm{I} .44(0.46-4.50)$ \\
\hline 5 & Secondary orbital implantation & 9 & 66.7 & $4.56(1.11-18.82)$ & 55.6 & $3.36(0.87-12.98)$ \\
\hline 6 & Orbital fracture repair & 8 & 62.5 & $3.73(0.87-16.09)$ & 37.5 & $1.55(0.36-6.69)$ \\
\hline \multirow[t]{2}{*}{7} & Strabismus surgery & 3 & 0 & - & 0 & - \\
\hline & Total & 212 & 32.1 & - & 28.3 & - \\
\hline
\end{tabular}

Note: RR (95\% confidence interval) for developing serious pain or discomfort.

Abbreviation: RR, relative risk.

showed no statistically significant impact on discomfort development, which was characterized by NRS score $\geq 5$ at any time postoperatively.

\section{Correlation between pain and discomfort scores}

The mean postoperative pain scores were positively correlated with postoperative discomfort scores in all 212 patients (Pearson $r=0.494 ; P<0.05$ ). A positive correlation was also observed between postoperative pain and discomfort at 0,2 , 6, 10, and 24 hours (Pearson $r=0.454,0.473,0.471,0.515$, and 0.539 , respectively; all $P<0.05$ ).

\section{Postoperative analgesic requirement}

Six patients $(2.8 \%)$ requested an analgesic agent at an average of $5.2(0.3-18)$ hours after surgery. They all received $0.5 \mathrm{~g}$ of paracetamol orally and experienced effective pain relief within 1 hour. The patients requiring analgesic drugs 
Table 2 Subgroup analyses of postoperative pain for Groups I, 5, and 6

\begin{tabular}{|c|c|c|c|c|c|}
\hline \multirow[t]{3}{*}{ Subgroup } & \multicolumn{5}{|c|}{ Numerical rating scale score } \\
\hline & 0 hours & 2 hours & 6 hours & 10 hours & 24 hours \\
\hline & Mean \pm SD & Mean \pm SD & Mean \pm SD & Mean \pm SD & Mean \pm SD \\
\hline \multicolumn{6}{|l|}{ Age, years } \\
\hline$<50(n=33)$ & $4.2 \pm 2.9$ & $3.4 \pm 2.3$ & $2.8 \pm 2.1$ & $2.5 \pm 2.2$ & $1.7 \pm 1.7$ \\
\hline$\geq 50(n=19)$ & $4.3 \pm 3.2$ & $4.1 \pm 2.7$ & $3.2 \pm 2.5$ & $2.6 \pm 2.5$ & $1.6 \pm 1.9$ \\
\hline$P$-value* & 0.88 & 0.34 & 0.57 & 0.90 & 0.90 \\
\hline \multicolumn{6}{|l|}{ Gender } \\
\hline Female $(n=18)$ & $4.4 \pm 2.7$ & $3.7 \pm 2.4$ & $3.6 \pm 2.3$ & $3.1 \pm 2.1$ & $1.8 \pm 1.9$ \\
\hline Male $(n=34)$ & $4.1 \pm 3.1$ & $3.6 \pm 2.6$ & $2.6 \pm 2.1$ & $2.3 \pm 2.4$ & $1.6 \pm 1.7$ \\
\hline$P$-value* & 0.71 & 0.82 & 0.10 & 0.28 & 0.64 \\
\hline \multicolumn{6}{|c|}{ Procedure duration, $\min$} \\
\hline$<120(n=39)$ & $4.5 \pm 3.0$ & $3.7 \pm 2.4$ & $2.8 \pm 2.2$ & $2.4 \pm 2.3$ & $1.7 \pm 1.7$ \\
\hline$\geq 120(n=13)$ & $3.2 \pm 2.5$ & $3.5 \pm 2.8$ & $3.2 \pm 2.4$ & $3.0 \pm 2.2$ & $1.7 \pm 1.9$ \\
\hline$P$-value* & 0.88 & 0.64 & 0.94 & 0.86 & 0.73 \\
\hline \multicolumn{6}{|l|}{ Smoking history } \\
\hline No $(n=4 I)$ & $3.9 \pm 2.8$ & $3.2 \pm 2.4$ & $2.6 \pm 2.2$ & $2.1 \pm 2.1$ & $1.3 \pm 1.6$ \\
\hline Yes $(n=I I)$ & $5.4 \pm 3.5$ & $5.2 \pm 2.1$ & $4.1 \pm 1.7$ & $4.1 \pm 2.4$ & $3.0 \pm 1.6$ \\
\hline$P$-value* & 0.02 & 0.02 & 0.05 & 0.01 & 0.00 \\
\hline \multicolumn{6}{|c|}{ Prior surgery on the other eye } \\
\hline No $(n=40)$ & $4.5 \pm 2.9$ & $3.6 \pm 2.9$ & $2.6 \pm 2.6$ & $2.7 \pm 2.2$ & $1.8 \pm 1.8$ \\
\hline Yes $(n=12)$ & $3.3 \pm 2.9$ & $3.6 \pm 2.9$ & $3.0 \pm 2.1$ & $2.3 \pm 2.7$ & $1.3 \pm 1.7$ \\
\hline$P$-value* & 0.23 & 0.94 & 0.55 & 0.68 & 0.34 \\
\hline \multicolumn{6}{|c|}{ Prior surgery on the operative eye } \\
\hline No $(n=36)$ & $4.1 \pm 3.2$ & $3.1 \pm 2.4$ & $2.4 \pm 2.0$ & $2.0 \pm 2.0$ & $1.2 \pm 1.5$ \\
\hline Yes $(n=16)$ & $4.4 \pm 2.4$ & $4.7 \pm 2.3$ & $4.1 \pm 2.2$ & $3.9 \pm 2.2$ & $2.8 \pm 1.8$ \\
\hline$P$-value* & 0.74 & 0.04 & 0.01 & 0.00 & 0.00 \\
\hline \multicolumn{6}{|l|}{ Local anesthesia } \\
\hline No $(n=40)$ & $4.1 \pm 3.1$ & $3.4 \pm 2.6$ & $2.6 \pm 2.2$ & $2.3 \pm 2.2$ & $1.4 \pm 1.7$ \\
\hline Yes $(n=12)$ & $4.8 \pm 2.4$ & $4.5 \pm 2.0$ & $4.1 \pm 2.0$ & $3.5 \pm 2.4$ & $2.5 \pm 1.8$ \\
\hline$P$-value* & 0.83 & 0.16 & 0.04 & 0.11 & 0.06 \\
\hline \multicolumn{6}{|l|}{ Analgesic history } \\
\hline No $(n=50)$ & $4.2 \pm 2.9$ & $3.6 \pm 2.4$ & $2.9 \pm 2.2$ & $2.6 \pm 2.3$ & $1.7 \pm 1.8$ \\
\hline Yes $(n=2)$ & $6.0 \pm 4.2$ & $3.5 \pm 5.0$ & $2.5 \pm 3.5$ & $2.5 \pm 0.7$ & $1.5 \pm 0.7$ \\
\hline$P$-value* & 0.39 & 0.95 & 0.79 & 0.96 & 0.89 \\
\hline \multicolumn{6}{|l|}{ Sedative history } \\
\hline No $(n=47)$ & $4.2 \pm 2.9$ & $3.7 \pm 2.4$ & $3.1 \pm 2.2$ & $2.6 \pm 2.3$ & $1.7 \pm 1.8$ \\
\hline Yes $(n=5)$ & $4.2 \pm 3.4$ & $3.2 \pm 3.3$ & $1.2 \pm 1.6$ & $2.0 \pm 1.9$ & $1.6 \pm 1.7$ \\
\hline$P$-value* & 0.98 & 0.70 & 0.07 & 0.56 & 0.92 \\
\hline \multicolumn{6}{|c|}{ Antiemetic use during the operation } \\
\hline No $(n=7)$ & $4.6 \pm 2.4$ & $4.4 \pm 2.3$ & $3.3 \pm 2.4$ & $3.7 \pm 2.8$ & $2.6 \pm 1.8$ \\
\hline Yes $(n=45)$ & $4.2 \pm 3.0$ & $3.5 \pm 2.5$ & $2.9 \pm 2.2$ & $2.4 \pm 2.2$ & $1.5 \pm 1.7$ \\
\hline$P$-value* & 0.75 & 0.36 & 0.64 & 0.16 & 0.15 \\
\hline \multicolumn{6}{|l|}{ SAS } \\
\hline$r$ & 0.17 & 0.25 & 0.37 & 0.25 & 0.40 \\
\hline$P$-value $\#$ & 0.24 & 0.08 & 0.01 & 0.07 & 0.00 \\
\hline
\end{tabular}

Notes: *Independent $t$-test; \#Pearson correlation analysis. Group I, orbital decompression; Group 5, secondary orbital implantation; Group 6, orbital fracture repair. The level of significance was set at $P<0.05$ via bolding in the table.

Abbreviations: SD, standard deviation; SAS, Self-rating Anxiety Scale.

included 1 orbital decompression patient, 3 enucleation or evisceration with orbital implantation patients, 1 secondary orbital implantation patient, and 1 orbital fracture repair patient. Postoperative analgesic requirement was shown to be associated with smoking history and pain scores at $0,6,10$, and 24 hours $(P<0.05)$. However, the other factors, including age, gender, procedure duration, prior surgery on the operative/another eye, local anesthesia administration, analgesic history, sedative history, antiemetic drug administration during the operation, SAS score, and discomfort score, showed no statistically significant impact on postoperative analgesic requirement (data not shown). 
Table 3 Subgroup analyses of postoperative discomfort for Groups I, 3, 5, and 6

\begin{tabular}{|c|c|c|c|c|c|}
\hline \multirow[t]{3}{*}{ Subgroup } & \multicolumn{4}{|c|}{ Numerical rating scale score } & \multirow{3}{*}{$\begin{array}{l}24 \text { hours } \\
\text { Mean } \pm \text { SD }\end{array}$} \\
\hline & 0 hours & 2 hours & 6 hours & 10 hours & \\
\hline & Mean \pm SD & Mean \pm SD & Mean \pm SD & Mean \pm SD & \\
\hline \multicolumn{6}{|l|}{ Age, years } \\
\hline$<50(\mathrm{n}=20)$ & $2.3 \pm 2.7$ & $2.7 \pm 2.8$ & $2.5 \pm 2.5$ & $2.5 \pm 2.6$ & $2.3 \pm 2.8$ \\
\hline$\geq 50(n=67)$ & $2.8 \pm 2.8$ & $2.8 \pm 2.7$ & $2.9 \pm 2.9$ & $3.0 \pm 2.8$ & $2.5 \pm 2.7$ \\
\hline$P$-value* & 0.43 & 0.81 & 0.56 & 0.40 & 0.87 \\
\hline \multicolumn{6}{|l|}{ Gender } \\
\hline Female $(n=28)$ & $3.2 \pm 2.7$ & $3.6 \pm 2.7$ & $3.7 \pm 2.8$ & $3.5 \pm 2.5$ & $2.9 \pm 2.4$ \\
\hline Male $(n=59)$ & $2.4 \pm 2.8$ & $2.4 \pm 2.7$ & $2.4 \pm 2.8$ & $2.6 \pm 2.9$ & $2.2 \pm 2.8$ \\
\hline$P$-value* & 0.25 & 0.05 & 0.05 & 0.17 & 0.28 \\
\hline \multicolumn{6}{|c|}{ Procedure duration, min } \\
\hline$<120(n=74)$ & $2.7 \pm 2.8$ & $2.8 \pm 2.7$ & $2.9 \pm 2.9$ & $3.0 \pm 2.8$ & $2.5 \pm 2.7$ \\
\hline$\geq 120(n=13)$ & $2.5 \pm 2.6$ & $2.9 \pm 2.8$ & $2.2 \pm 2.4$ & $2.2 \pm 2.0$ & $2.0 \pm 2.4$ \\
\hline$P$-value* & 0.85 & 0.93 & 0.41 & 0.29 & 0.53 \\
\hline \multicolumn{6}{|l|}{ Smoking history } \\
\hline No $(n=67)$ & $2.8 \pm 2.8$ & $2.8 \pm 2.8$ & $2.8 \pm 2.9$ & $3.0 \pm 2.9$ & $2.3 \pm 2.6$ \\
\hline Yes $(n=20)$ & $2.3 \pm 2.7$ & $2.8 \pm 2.6$ & $2.9 \pm 2.6$ & $2.7 \pm 2.3$ & $3.0 \pm 2.6$ \\
\hline$P$-value* & 0.49 & 0.95 & 0.90 & 0.70 & 0.33 \\
\hline \multicolumn{6}{|c|}{ Prior surgery on the other eye } \\
\hline No $(n=74)$ & $2.8 \pm 2.8$ & $2.8 \pm 2.7$ & $3.0 \pm 2.2$ & $3.0 \pm 2.8$ & $2.5 \pm 2.7$ \\
\hline Yes $(n=13)$ & $2.0 \pm 2.5$ & $2.7 \pm 2.8$ & $2.2 \pm 2.2$ & $2.2 \pm 2.4$ & $1.9 \pm 2.2$ \\
\hline$P$-value* & 0.34 & 0.90 & 0.35 & 0.29 & 0.39 \\
\hline \multicolumn{6}{|c|}{ Prior surgery on the operative eye } \\
\hline No $(n=58)$ & $2.7 \pm 2.7$ & $2.8 \pm 2.5$ & $2.8 \pm 2.7$ & $2.9 \pm 2.9$ & $2.4 \pm 2.8$ \\
\hline Yes $(n=29)$ & $2.6 \pm 3.0$ & $2.8 \pm 3.1$ & $2.8 \pm 3.0$ & $2.9 \pm 2.6$ & $2.6 \pm 2.5$ \\
\hline$P$-value* & 0.89 & 0.91 & 1.00 & 0.91 & 0.71 \\
\hline \multicolumn{6}{|l|}{ Local anesthesia } \\
\hline No $(n=46)$ & $2.9 \pm 0.2$ & $3.1 \pm 3.0$ & $3.0 \pm 3.1$ & $2.7 \pm 2.9$ & $2.4 \pm 2.9$ \\
\hline Yes $(n=4 I)$ & $2.4 \pm 2.3$ & $2.5 \pm 2.3$ & $2.6 \pm 2.5$ & $3.1 \pm 2.6$ & $2.5 \pm 2.5$ \\
\hline$P$-value* & 0.41 & 0.30 & 0.55 & 0.55 & 0.81 \\
\hline \multicolumn{6}{|l|}{ Analgesic history } \\
\hline No $(n=80)$ & $2.7 \pm 2.8$ & $2.8 \pm 2.7$ & $2.9 \pm 2.9$ & $2.9 \pm 2.8$ & $2.4 \pm 2.7$ \\
\hline Yes $(n=7)$ & $2.7 \pm 3.1$ & $2.4 \pm 3.0$ & $2.1 \pm 2.5$ & $3.6 \pm 3.2$ & $3.1 \pm 3.0$ \\
\hline$P$-value* & 0.97 & 0.72 & 0.51 & 0.51 & 0.47 \\
\hline \multicolumn{6}{|l|}{ Sedative history } \\
\hline No $(n=82)$ & $2.6 \pm 2.8$ & $2.7 \pm 2.7$ & $2.8 \pm 2.7$ & $3.0 \pm 2.8$ & $2.4 \pm 2.7$ \\
\hline Yes $(n=5)$ & $4.4 \pm 2.5$ & $3.6 \pm 2.5$ & $3.4 \pm 2.7$ & $2.2 \pm 2.2$ & $2.6 \pm 3.3$ \\
\hline$P$-value* & 0.15 & 0.49 & 0.64 & 0.56 & 0.89 \\
\hline \multicolumn{6}{|c|}{ Antiemetic use during the operation } \\
\hline No $(n=14)$ & $3.7 \pm 2.6$ & $3.4 \pm 2.4$ & $3.7 \pm 2.5$ & $3.8 \pm 2.9$ & $3.1 \pm 2.8$ \\
\hline Yes $(n=73)$ & $2.5 \pm 2.8$ & $2.7 \pm 2.8$ & $2.7 \pm 2.9$ & $2.7 \pm 2.8$ & $2.3 \pm 2.6$ \\
\hline$P$-value* & 0.13 & 0.33 & 0.20 & 0.20 & 0.28 \\
\hline \multicolumn{6}{|l|}{ SAS } \\
\hline$r$ & 0.11 & 0.22 & 0.16 & 0.28 & 0.30 \\
\hline$P$-value ${ }^{\#}$ & 0.31 & 0.04 & 0.14 & 0.01 & 0.00 \\
\hline
\end{tabular}

Notes: *Independent $t$-test; \#Pearson correlation analysis. Group I, orbital decompression; Group 3, enucleation or evisceration with orbital implantation; Group 5, secondary orbital implantation; Group 6, orbital fracture repair. The level of significance was set at $P<0.05$ via bolding in the table.

Abbreviations: SD, standard deviation; SAS, Self-rating Anxiety Scale.

\section{Discussion}

The purpose of this study was to evaluate postoperative pain and discomfort following oculoplastic surgery under general anesthesia and to analyze factors associated with their development. Occasionally, ophthalmic surgery is considered to cause severe postoperative pain, with limited trauma compared with other surgical disciplines. ${ }^{3}$ Therefore, there are only a few published studies on this topic. In recently published studies, complex ophthalmic surgery ${ }^{5}$ and surgery under general anesthesia ${ }^{3}$ were found to lead to severe postoperative pain. Moreover, pain decreased at 24 hours after the visit. ${ }^{6}$ However, the possible factors associated with increased postoperative pain and discomfort in this context are unknown. Our aim was to prospectively gather 
valid data on the development of pain and discomfort after oculoplastic surgery.

In patients undergoing ophthalmic surgery, several ophthalmic surgical procedures were associated with significantly different postoperative pain intensities. ${ }^{4}$ The prevalence of severe pain following enucleation was up to $42.9 \%$, whereas this prevalence following cataract, iridectomy, and anterior chamber revision was only $13.8 \%{ }^{3}$ Similarly, major operations performed in this study, such as orbital decompression, secondary orbital implantation, and orbital fracture repair, were more likely to induce significant postoperative pain, with a pain intensity of $51.9 \%$, compared with other minor ophthalmic surgical procedures, which resulted in a pain intensity of $26.0 \%$.

Earlier studies on the factors associated with postoperative pain in ophthalmic surgery revealed a lack of studies in this field. ${ }^{4}$ Gender (female), a longer duration of the surgical procedure, a second ophthalmic surgery as a consecutive procedure, the type of surgery, and general anesthesia may contribute to increased postoperative pain intensity. ${ }^{4}$ Based on the multivariate analyses performed in this study, the independent predictors of average postoperative pain intensity were smoking history, prior surgery on the operative eye, and anxiety.

In this study, smoking history was strongly associated with postoperative pain at almost all time points observed, and these patients required more postoperative analgesic medication, which was not demonstrated in previous ophthalmic surgery studies. One study revealed that current smokers required more morphine than non-smokers and past smokers during the 72 hours after other types of surgery. ${ }^{12}$ However, the potential mechanisms of the interaction between smoking and acute postoperative pain are complex and not fully understood. ${ }^{13}$

Prior surgery on the operative eye also resulted in a significantly greater postoperative pain intensity in our study. Similarly, a study of patients undergoing two consecutive cataract surgeries also indicated that patients had significantly more pain following the second operation. ${ }^{14}$ Several mechanisms have been proposed to explain why patients experience more pain during the second surgery; for example, surgery in the first eye may cause sympathetic irritation that results in sensitization of the second eye,${ }^{15}$ and pain during the second surgery may be associated with altered patient expectations and increased awareness. ${ }^{16,17}$

Anxiety was identified as an important predictor for the development of postoperative pain. ${ }^{18}$ It has been described that an anxious state leads to increased reactivity to pain, supporting the view that emotional states modulate human pain reactivity. ${ }^{19}$ Similarly, in this study, anxiety was more likely to lead to significant postoperative pain. Therefore, a prospective, well-defined protocol including the identification of patients with anxiety and the management of these patients, preferably with selected medical workers using the same methods for the management of the patients, would be of greater significance.

Regional anesthesia is preferred over general anesthesia for ocular surgery because of reduced anesthetic requirements, enabling rapid emergence and good postoperative analgesia. However, complex ophthalmic surgeries in our series with local anesthesia did not appear to result in less postoperative pain, which we considered to be related to the complex surgical procedures and the analgesic drugs used during surgery.

As previously stated, patient preference for a postoperative treatment does not appear to be based only on pain experience. ${ }^{20}$ Other factors, including nausea, vomiting, headache, and dizziness, may play important roles. Furthermore, with the major shift from the traditional postoperative hospitalization course towards ambulatory surgery on an outpatient basis, patient safety and comfort in the postoperative period are of the utmost importance when evaluating outpatient procedures. ${ }^{6}$ As previously reported, when not treated prophylactically, one third of surgical patients experience postoperative nausea and vomiting (PONV). ${ }^{21}$ The incidence of PONV was found to be significantly higher following eye surgery, ${ }^{22}$ especially after complex oculoplastic surgeries, as $75 \%$ and $37 \%$ of patients experienced nausea following orbital hydroxyapatite implant surgery ${ }^{23}$ and strabismus surgery ${ }^{24}$ respectively, but only $23 \%$ experienced nausea after vitrectomy. ${ }^{25}$ On the other hand, opioids including fentanyl and remifentanil, ${ }^{21}$ which were used in our cases, can cause PONV through various mechanisms. ${ }^{26}$ Our study showed that complex oculoplastic surgeries, such as orbital decompression, enucleation/ evisceration with orbital implantation, secondary orbital implantation, and orbital fracture repair, were more likely to induce significant postoperative discomfort in patients, with $41.4 \%$ patients reporting significant discomfort. However, this risk could be reduced by various methods: propofol and antiemetic use reduced the incidence of postoperative discomfort by $19 \%$ and $26 \%$, respectively. ${ }^{21}$ In this study, propofol was used extensively in all cases; and antiemetics were also used in most cases, which reduced discomfort scores by $0.7-1.2$, although no statistically significant differences were observed. The discomfort scores of all patients decreased to less than 4 at 24 hours with the use of propofol and antiemet- 
ics. Additionally, an anxious state leads to increased reactivity to discomfort, but the postoperative discomfort scores were still lower than 4 among anxious patients, suggesting that outpatient orbital surgery, when performed by an experienced orbital surgeon, is safe and well tolerated. ${ }^{6}$

In conclusion, some oculoplastic surgeries are likely to result in postoperative pain and discomfort. Anxiety is a risk factor for both postoperative pain and discomfort, while smoking history and prior surgery on the operative eye may lead to postoperative pain. Awareness of these factors may help health care workers improve postoperative pain and discomfort management in oculoplastic surgery.

\section{Acknowledgements}

This work was supported by the National Natural Science Foundation of China $(81700875 ; 81530028 ; 81721003)$, the Sun Yat-Sen University Clinical Research 5010 Program, China (2014014), and the Guangdong Province Science \& Technology Plan (2014B020228002). The sponsors had no role in the study design, survey process, data analysis, and manuscript preparation.

Huijing Ye, Rongxin Chen, and Xiufen Lian should be considered as co-first authors.

\section{Author contributions}

All authors contributed toward data analysis, drafting and critically revising the paper and agree to be accountable for all aspects of the work.

\section{Disclosure}

The authors report no conflicts of interest related to this work.

\section{References}

1. Myles PS, Williams DL, Hendrata M, Anderson H, Weeks AM. Patient satisfaction after anaesthesia and surgery: results of a prospective survey of 10,811 patients. Br J Anaesth. 2000;84(1):6-10.

2. Sommer M, Geurts JW, Stessel B, et al. Prevalence and predictors of postoperative pain after ear, nose, and throat surgery. Arch Otolaryngol Head Neck Surg. 2009;135(2):124-130.

3. Henzler D, Kramer R, Steinhorst UH, Piepenbrock S, Rossaint R, Kuhlen $R$. Factors independently associated with increased risk of pain development after ophthalmic surgery. Eur J Anaesthesiol. 2004;21(2):101-106.

4. Lesin M, Domazet Bugarin J, Puljak L. Factors associated with postoperative pain and analgesic consumption in ophthalmic surgery: a systematic review. Surv Ophthalmol. 2015;60(3):196-203.

5. Lesin M, Sundov ZD, Jukic M, Puljak L. Postoperative pain in complex ophthalmic surgical procedures: comparing practice with guidelines. Pain Med. 2014;15(6):1036-1042.
6. Korn BS, Kikkawa DO, Vasani SN, et al. Evaluation of patient comfort with outpatient orbital surgery. Orbit. 2007;26(1):19-22.

7. Fekrat S, Elsing SH, Raja SC, Campochiaro PA, de Juan E, Jr., Haller JA. Eye pain after vitreoretinal surgery: a prospective study of 185 patients. Retina. 2001;21(6):627-632.

8. Downie WW, Leatham PA, Rhind VM, Wright V, Branco JA, Anderson JA. Studies with pain rating scales. Ann Rheum Dis. 1978;37(4):378-381.

9. Ferraz MB, Quaresma MR, Aquino LR, Atra E, Tugwell P, Goldsmith $\mathrm{CH}$. Reliability of pain scales in the assessment of literate and illiterate patients with rheumatoid arthritis. J Rheumatol. 1990;17(8):1022-1024.

10. Jensen MP, McFarland CA. Increasing the reliability and validity of pain intensity measurement in chronic pain patients. Pain. 1993;55(2):195-203.

11. Price DD, Bush FM, Long S, Harkins SW. A comparison of pain measurement characteristics of mechanical visual analogue and simple numerical rating scales. Pain. 1994;56(2):217-226.

12. Chiang HL, Chia YY, Lin HS, Chen CH. The implications of tobacco smoking on acute postoperative pain: a prospective observational study. Pain Res Manag. 2016;2016:9432493.

13. ShiY, Weingarten TN, Mantilla CB, Hooten WM, Warner DO. Smoking and pain: pathophysiology and clinical implications. Anesthesiology. 2010;113(4):977-992.

14. Aslan L, Aslankurt M, Cekic O, Aksoy A, Yildiz H. The pain experience and cooperation of patients in consecutive cataract surgery. Eur $J$ Ophthalmol. 2013;23(3):339-343.

15. El Rami H, Fadlallah A, Fahd D, Fahed S. Patient-perceived pain during laser in situ keratomileusis: comparison of fellow eyes. $J$ Cataract Refract Surg. 2012;38(3):453-457.

16. Pud D, Golan Y, Pesta R. Hand dominancy--a feature affecting sensitivity to pain. Neurosci Lett. 2009;467(3):237-240.

17. Ursea R, Feng MT, Zhou M, Lien V, Loeb R. Pain perception in sequential cataract surgery: comparison of first and second procedures. $J$ Cataract Refract Surg. 2011;37(6):1009-1014.

18. Ip HY, Abrishami A, Peng PW, Wong J, Chung F. Predictors of postoperative pain and analgesic consumption: a qualitative systematic review. Anesthesiology. 2009;111(3):657-677.

19. Rhudy JL, Meagher MW. Fear and anxiety: divergent effects on human pain thresholds. Pain. 2000;84(1):65-75.

20. Checchi L, Trombelli L. Postoperative pain and discomfort with and without periodontal dressing in conjunction with $0.2 \%$ chlorhexidine mouthwash after apically positioned flap procedure. J Periodontol. 1993;64(12):1238-1242.

21. Apfel CC, Korttila K, Abdalla M, et al. A factorial trial of six interventions for the prevention of postoperative nausea and vomiting. $N$ Engl J Med. 2004;350(24):2441-2451.

22. Aftab S, Khan AB, Raza G. Assessment of risk factors for postoperative nausea and vomiting. J Coll Physicians Surg Pak. 2008;18(3): $137-141$.

23. Waterman H, Slater R, Leatherbarrow B, Waterman C, Hillier V. Postoperative nausea and vomiting following orbital hydroxyapatite implant surgery. Eur J Anaesthesiol. 1998;15(5):590-594.

24. Kuhn I, Scheifler G, Wissing H. Incidence of nausea and vomiting in children after strabismus surgery following desflurane anaesthesia. Paediatr Anaesth. 1999;9(6):521-526.

25. Nitahara K, Sugi Y, Shono S, Hamada T, Higa K. Risk factors for nausea and vomiting following vitrectomy in adults. Eur J Anaesthesiol. 2007;24(2):166-170.

26. Rama-Maceiras P, Ferreira TA, Molins N, Sanduende Y, Bautista AP, Rey $\mathrm{T}$. Less postoperative nausea and vomiting after propofol + remifentanil versus propofol + fentanyl anaesthesia during plastic surgery. Acta Anaesthesiol Scand. 2005;49(3):305-311. 
The Journal of Pain Research is an international, peer reviewed, open access, online journal that welcomes laboratory and clinical findings in the fields of pain research and the prevention and management of pain. Original research, reviews, symposium reports, hypothesis formation and commentaries are all considered for publication
The manuscript management system is completely online and includes a very quick and fair peer-review system, which is all easy to use. Visit http://www.dovepress.com/testimonials.php to read real quotes from published authors. 